\title{
THE CHALLENGES POSED BY PROBLEM SOILS ON THE PERFORMANCE OF ROAD PAVEMENTS: REVIEW OF A TANZANIAN MANUAL FOR PAVEMENT DESIGN AND MATERIALS
}

\author{
RICHARD ROBERT MWAIPUNGU ${ }^{1} \&$ SABRY AHMED ${ }^{2}$ \\ ${ }^{1}$ Mkwawa University College of Education, Tanzania \\ ${ }^{2}$ Brightwave Construction Company, Tanzania
}

\begin{abstract}
When problem soils form part of pavement or bed layers, they may negatively influence the performance of the pavement, if not appropriately addressed during the design stage. This can be readily noted in the way they impede free vehicles' movement. This effect is due to the pavement's conspicuous changes in load-bearing capacity with climatic changes, leading to pavement distress as a result of their structural deformation. The variations of these soils' load-bearing capacity, which lead to pavement distress, are mainly related to these soils' changes in moisture content during the dry and wet seasons. It is an established fact that the structure and behaviour of problematic soils varies with the origin and type of soil mineralogy, location, stress history and climate. These factors have immense influence on the design, construction and management of the sealed and unsealed roads' pavements. In an effort to address problem soils' challenges, Tanzania's Ministry of Works Pavement and Materials Design Manual (TMoW-P\&MDM), which came into being in 1999, has attempted to describe the measures that need to be taken to improve problem soils' performance, when encountered as part of pavement layers or the roadbed. These measures vary in complexity depending on the type of problematic soil in question. This paper looks at the identification and classification of challenging clay soils, as given by $T M o W-P \& M D M$, as a tool for appropriate remedial measures to be put in place, and makes global comparisons. Furthermore, this paper stresses the need for legal framework to compel conducting the preliminary site investigation. The authors' opinion is that further improvement of local prediction models of problematic soils' negative effects will come with an understanding of the key roles played by soil characteristics in influencing negative behaviour. Performance studies of soils under the interaction of traffic's wheel loads and climatic changes will further add to said improvement.
\end{abstract}

Keywords: clay, manual, pavement performance, roadbed, road design, soils, traffic, weather, wheel loads.

Soil can be described as:

\section{INTRODUCTION}

- Representing tri-dimensional bodies in or on Earth's surface;

- Being made up of mineral compounds, organic compounds and living organisms interacting each other;

- Resulting from paedogenetic processes associated with geologic and geomorphic conditions and processes acting over time;

- Able to continuously exchange energy and substance with the environment; and

- Having their own specific organization and development.

Based on the method of deposition, soil can be grouped into two major categories: residue and transported soils. Residue soils were formed from the weathering of rocks and remain at the location of their origin. Residue soils include particles of a wide range of sizes, shapes and compositions; depending on the duration and type of weathering and the 
minerals in the parent rock. Transported soils are those materials that have been moved from their place of origin. The medium of transport could be: gravity, wind, water, glaciers or human activities. Transported soils are often segregated according to size, during the transportation process. The method of transportation and deposition has significant effects on the resulting soil mass properties. The processes for soil deposition are still effective, to date.

Before embarking on pavement design, the type and condition of soil deposits underlying the proposed road construction site must be reckoned with by the civil engineers concerned [1] through site investigation, which aims to identify the soil's composition, structure and characteristics. The structure and characteristics of problematic soils (in this paper they shall also be known as challenging soils) varies with the origin and type of soil, climate, location, and stress history. All these variations influence the design, construction, and management of road pavements; hence, those responsible for the design of pavement structures need to take into consideration any in situ soil characteristics, in order to identify any challenging soils and deal with them accordingly.

To be able to predict the future behaviour of the soil and do a proper pavement foundation design, the following information about the soil is necessary; namely, the profile, position of the water table, existence and extent of rock, and the expected engineering properties of the soil. The information can be obtained by indirect and direct methods, as described in Table 1 [2]. The prime requirement for successful foundation design is and always will be a good site investigation, carried out with knowledge of the requirements of the proposed structure [3]. A deep knowledge of the geotechnical properties and behaviour of challenging soils is paramount in engineering analysis of pavement sub-grades and slope stability [4].

\section{SITE INVESTIGATIONS}

The site investigations to identify problem soils may adhere to the following stages, namely: 1. Routine investigation; 2. Extended investigation; and 3. In-depth studies [5].

\subsection{Routine, extended and in-depth investigations}

Routine investigations include analysis of soil survey data from the proposed pavement centreline and site observations carried out as part of design work. Site observations include simple geological and geomorphologic assessments, as well as field reconnaissance. Laboratory tests include Atterberg limits, grading, and analysis of test data. Extended investigations include testing of shrinkage limits; calculation of expansiveness from a given

Table 1: Methodology to determine soil mass characteristics.

\begin{tabular}{|l|l|}
\hline Indirect Methods & Direct Methods \\
\hline Study of geological maps & Study on site of nearby existing structures \\
\hline $\begin{array}{l}\text { Study and interpretation of soil-engineering } \\
\text { maps }\end{array}$ & In situ strength tests \\
\hline $\begin{array}{l}\text { Study of reports on nearby existing } \\
\text { structures }\end{array}$ & $\begin{array}{l}\text { Digging and profiling of test holes or } \\
\text { excavations and selection of samples for } \\
\text { laboratory testing }\end{array}$ \\
\hline Study of old maps and aerial photos & $\begin{array}{l}\text { Sinking of bore holes and sampling of } \\
\text { cores for identification and testing }\end{array}$ \\
\hline Google earth images & Performance of field tests for identification \\
\hline
\end{tabular}


formula; and classification into low, medium and high expansiveness. In-depth studies include specialised laboratory testing to quantify the swell potential [5].

\section{SOIL STRUCTURE}

A soil's structure may be defined as any system that has the sole function of transmiting load. The engineering behaviour of an in situ soil is a function of its structure (fabric), which in turn is the result of geological conditions governing the soil's deposition and its subsequent history of stressing and weathering [6].

Historically, two types of soil structure have been differentialed for engineering purposes, the primary structure and the secondary structure.

\subsection{Primary structure}

This refers to the manner in which the sand, silt, and clay particles in the soil mass are arranged into compound aggregates or peds. Karl Terzagh has classified undisturbed soils with regard to primary structure, such as single-grained, honeycomb, and flocculent. This classification recognizes that structure is dependent upon particle size and shape, as well as upon the minerals comprising the individual grains. Single-grained structure is usually associated with the coarse-grained sands and gravels. Honeycomb structure is most often associated with water-deposited silt-sized soil particles, while a flocculent structure is generally associated with clay soils that were formed in large bodies of water. This assertion implies that all challenging soils have either honeycomb or flocculent structures.

\subsection{Secondary structure}

The secondary structure came into being due to modification of the primary structure during prolonged consolidation, followed by a stress relief and swelling process caused by erosion of overburden, and chemical and physical weathering. Secondary structures are associated with fissures and cracks, being slickensided, having concretions and other discontinuities that sometimes develop subsequent to a soil's formation or deposition.

\subsubsection{Micro and macro soil structures}

Soil structure can exist at micro or macro levels. These two levels are differentiated based on the presence (or absence) of joints in the soil, as well as the nature of these joints [7].

According to Barden [8], soils in which the micro structure dominates engineering behaviour in the mass include: sensitive and quick clays, collapsing sands, loesses, compressible creep-prone clays, peats, expansive clays, shales, residue and lateritic clays. Soils in which the macro structure predominates include features such as: horizontal layering, laminations and varves, vertical root channels and tension cracks, and random fissuring and jointing. From the above one can easily deduce that the most challenging soils fall into micro structures or primary structures, while the macro structures are associated with secondary structures.

\section{CHALLENGING SOILS}

\subsection{Definition}

Challenging soil in road construction is any soil having an effect on the performance of a pavement due to induced stresses and strains following movements caused by volume changes in the subgrade materials [9]. According to Saad [10], challenging soils are soil 
that cause additional problems from the engineering point of view, as a result of the circumstances of its composition or a change in environmental conditions. The Fairfax country [11] code defines challenging soils as soils that are susceptible to landslide, shrinking and swelling; soils with high water table conditions; soils containing hazardous materials, buried waste sites, un-compacted and undocumented man-placed fills; and earthen structures that would require special precautions for safety during and after the construction activity.

\subsection{Characteristics of challenging soils}

Soils can be determined to be challenging from the geotechnical engineering point of view when they expand, collapse, disperse, undergo excessive settlement, have a distinct lack of strength, or are soluble. Such characteristics may be attributable to their composition, the nature of their pore fluid, their mineralogy or their fabric (structure) [12]. Soils can be challenging naturally or in a manmade way. Soils with good characteristics, such as for road-building materials, can become challenging soils through changes in characteristics, by [13]:

- Inappropriate supervision during design, construction and maintenance;

- Lack of adequate and/or timely maintenance to suit the local characteristics, in terms of: climate, terrain, soil type, and traffic spectrum; and

- Inappropriate handling during the winning process, transportation, and dumping.

\subsection{Description and types of challenging soil}

According to the $T M o W-P \& M D M[5]$, challenging soils can be categorised in four groups, based on having low strength in terms of the California Bearing Ratio (CBR) or its' having unfavourable behaviour or composition, namely being:

- expansive soils;

- dispersive soils;

- organic soils; and

- $\quad$ saline soils.

Although the list is not exhaustive, it might suffice for the purpose of the $T M o W$ $P \& M D M$. Rogobete and Grozav [9] categorise challenging soils as: quick-sand, collapsible soil, expansive clay, dispersive soil and peat soil. According to Airey [14], there are 22 problematic soils so far that are known:

1. Collapsible soils;

2. Unsaturated soils;

3. Volcanic soils;

4. Carbonate soils;

5. Manmade fills;

6. Expansive soils;

7. Unsaturated soils;

8. Shales and clay stones;

9. Dispersive soils;

10. Silts;

11. Liquefiable soils;
12. Saline soils;

13. Acid-sulphate soils;

14. Residual soils;

15. Laterites;

16. Peat and organic soils;

17. Gassy soils;

18. Quick clays/sands;

19. Waste materials;

20. Mined materials;

21. Mine wastes; and

22. Tailings. 
If we go by the definition of challenging soils, then the list will vary from location to location. Table 2 describes the features of expansive soil.

\section{GENESIS OF PROBLEM SOILS}

The five basic factors influencing the formation of soil may be listed as:

1. Parent material;

2. Topography;

3. Climate;

4. Living organisms; and

5. Time.

In any particular region, the last three of these factors may be sensibly constant, yet considerable variation may occur in the properties of soil. This particularly explains the great importance of geological formation and of landform in the prediction of both distribution and behaviour of problematic soils.

The source of the problems ascribed to challenging soils, such as are known in this paper, can be summarised as follows [14]:

- A failure to understand the geology;

- Inadequate site investigation;

- Inappropriate specification of laboratory and field tests;

- Failure to interpret data correctly;

- Failure to use appropriate theoretical models;

- Inappropriate use of correlations; and

- Lack of experience.

According to Terzagh, natural soil in never uniform: its properties change from point to point while our knowledge of its properties is limited to those few spots at which the samples have been collected.

\subsection{Significance of empirical and theoretical approach in understand problematic soils}

According to Burland et al. [3], although local practice often results in considerably over-designed foundations, there are also numerous cases where the 'educated guess' based on routine index tests is likely to have at least the same certainty of success, in terms of economy and performance, as a more formal design that is based on quantitative soil testing and analysis. This all points to the fact that testing and computation form only one aspect of foundation design. A close study of local practice or experience provides direct evidence of what can be and of what cannot be achieved. To the experienced engineer, the information can be of more direct value in design than accurately determined

Table 2: Descriptive features of expansive soils.

\begin{tabular}{|l|l|}
\hline Soil description & Typical features of expansive soils \\
\hline Soil type & The more 'clayey' the soil, the more likely to be expansive \\
\hline $\begin{array}{l}\text { Consistency when slightly } \\
\text { moist or dry }\end{array}$ & Stiff to very stiff \\
\hline Consistency when wet & Soft to firm and sticky \\
\hline Structure & Typical cracked surface, slick-sided fissures (Fig. 1) \\
\hline Colour & Only a reliable indicator when combined with local knowledge \\
\hline Local knowledge from road projects in the area is invaluable \\
\hline
\end{tabular}




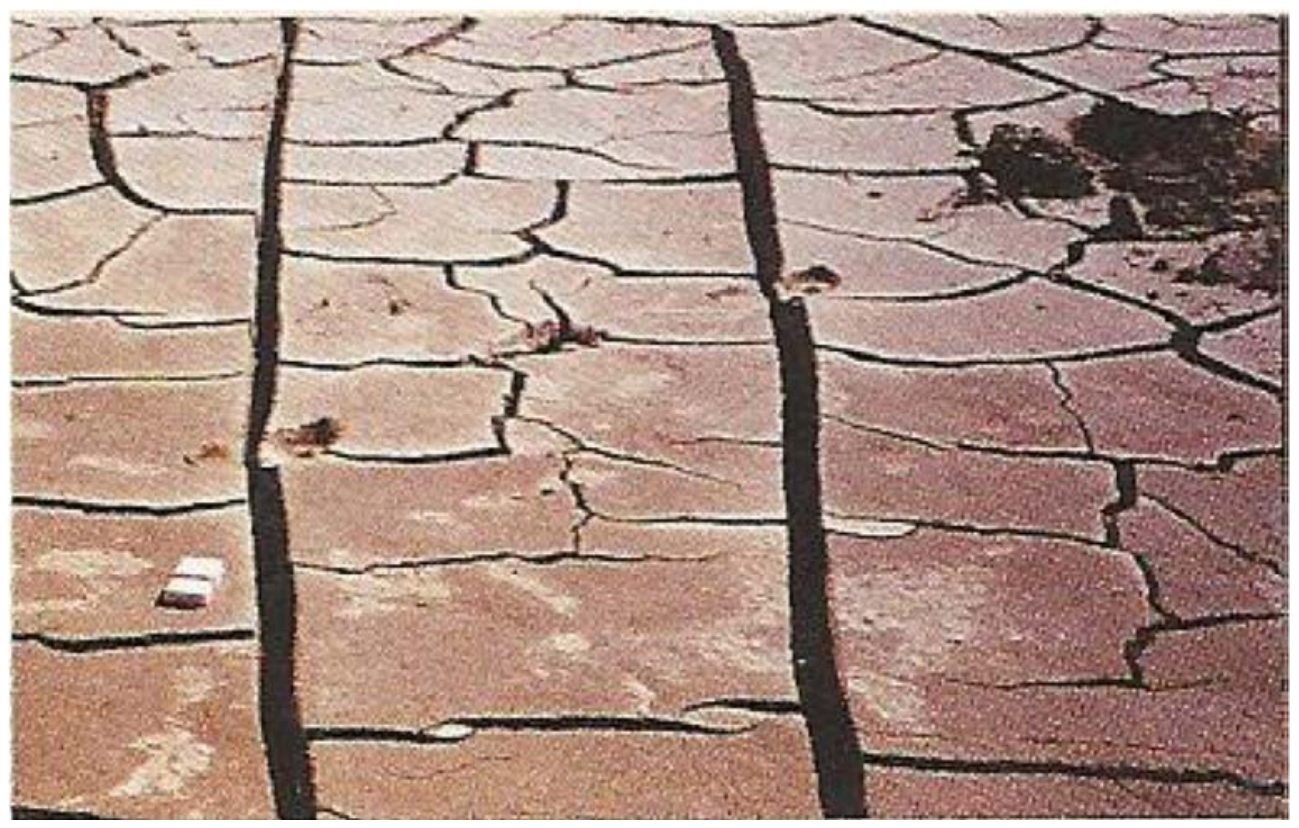

Figure 1: Typical features of expansive soils - swell and shrinkage [5].

soil parameters, because it carries with it so many facets of the behaviour of the ground and structure which can never be calculated.

More valuable still is the local experience based on quantitative observations of performance. Bowles [15] stresses that due to the heterogeneous nature of soil and rock masses, two foundations, even on adjacent construction sites, will seldom be the same except by coincidence. Because every foundation represents at least partly a venture into the unknown, it is of great value to have access to others' solutions, as obtained from conference presentations, journal papers, and textbooks' condensations of appropriate literature. The amalgamation of experience of what others have done in somewhat similar situations and the site-specific geotechnical information needed to produce an economical, practical and safe substructure design is seen in the application of engineering judgement [15].

\section{IDENTIFICATION AND CLASSIFICATION OF CHALLENGING SOILS}

\subsection{Identification}

It is important to identify expansive soils at an early stage of a given project, so as to allow for appropriate sampling, testing and design in the later stages [16]. Elarabi [16] further stresses that the purpose of identification of challenging soils is to provide a rational basis for soil characterization, to warn against expected potential hazards and help in the project's foundation selection. Identification of challenging soils normally form part of the soil investigation exercise, which must comprise two important phases [16], namely:

1. Recognition and identification of the soil as expansive or challenging soils; and 
2. Sampling and measurement of material properties to be used as the basis for design predictions. Once the above procedure has been adhered to regarding the problem soils, these cease to be a problem anymore, but instead are a challenge to be tackled.

Clay mineralogy is a fundamental factor controlling expansive soil behaviour. Clay minerals can be identified using a variety of techniques. The most commonly employed techniques are visual identification and mineralogical identification. The presence of vegetation can be an indicator of the existence of an expansive soil.

\subsection{Classification}

One of the important aspects regarding laboratory testing of challenging soils, once identified, is to classify them according to their degree of major characteristics, be that by expansiveness for expansive soils or sodic nature for dispersive soils. Any system of soil classification involves grouping soils into categories that possess similar properties, thus providing a systematic method of soil description by which soil can be identified quickly.

Expansiveness of the soil is a convenient expression to classify predicted heave as a result of swelling in expansive soils, although heave depends on a number of other factors, such as the conditions under which the soil performs in the road, including initial moisture content, density and suction; plus lateral support, vertical stress, and stress history. Saad [10] is of the opinion that these soils can also be classified according to the percentage of clay soil present; as the amount of clay soil present in a soil is a fundamental reason behind volume changes in problematic soils. The expansiveness of the soil is; however, a practically measurable parameter that makes it possible to classify the expected severity of the problem, as shown in Table 3 [5].

According to Cerato and Lutenegger [17], Specific Surface Area (SSA) and Cationic Exchange Capacity (CEC) are additional fundamental soil properties that dominate finegrained soil behaviour, and they may be a more fundamental and convenient basis for describing the mineralogical composition of fine-grained soils. SSA refers to the area per unit weight of soil, and it is usually expressed as $\mathrm{m} 2 / \mathrm{g}$; while CEC refers to the number of cations in the double layer that can easily be replaced or exchanged by other cations introduced into the solution and is traditionally reported in milliequivalents of cations per $100 \mathrm{~g}$ of soil. Both the SSA and the CEC of a soil are considered 'inherent' soil properties that do not change with water content, pore fluid chemistry, and time; and therefore, are more fundamental in describing and classifying fine-grained soil behaviour.

Expansiveness and Expansion Index are determined from different expressions, but all measure and classify the same behaviour of expansive soils. From Table 3 one can note that the three classification points used by TMoW-P\&MDM are not exhaustive, in comparison with the one employed by the American Society of Testing Material (ASTM).

Table 3: Classification of challenging soils based on expansiveness and expansion index.

\begin{tabular}{|c|c|c|c|}
\hline Expansiveness (8ex) & $\begin{array}{c}\text { Expansion Index } \\
\text { (EI) }\end{array}$ & \multicolumn{2}{|c|}{ Classification } \\
\hline TMoW-P\&MDM & ASTM & TMoW-P\&MDM & ASTM \\
\hline$<20$ & $0-20$ & Low & Very Low \\
\hline $20-50$ & $21-50$ & Medium & Low \\
\hline$>50$ & $51-90$ & High & Medium \\
\hline- & $91-130$ & - & High \\
\hline- & $>130$ & - & Very High \\
\hline
\end{tabular}




\subsubsection{Calculation of expansiveness}

According to $T M o W-P \& M D M$ [5], expansiveness $\left(\varepsilon_{\mathrm{ex}}\right)$ is calculated on the basis of extended investigation on the soil Atterberg limits and is calculated from eqn (1):

$$
\varepsilon_{\mathrm{ex}}=2.4 \mathrm{w}_{\mathrm{p}}-3.9 \mathrm{w}_{\mathrm{s}}+32.5,
$$

where $\mathrm{w}_{\mathrm{p}}$ is plastic limit and $\mathrm{w}_{\mathrm{s}}$ is shrinkage limit, both weighted for the samples' actual content of particles $<425 \mu \mathrm{m}$.

The American Society of Testing Materials (ASTM D 4829) published a test method to determine per cent swell and eqn (2) to determine Expansion Index for classification purposes, as indicated in Table 3.

$$
\mathrm{EI}=100 \times \Delta \mathrm{h} \times \mathrm{F},
$$

where $\Delta \mathrm{h}$ is per cent swell, and $\mathrm{F}$ is the fraction able to pass through a No. 4 sieve.

For non-plastic soils, eqn (1) gives the expansiveness of 32.5, which is classified as medium as per Table 3 . The two parameters employed in the equation do not sit well with those representing the mineralogy of swelling clays, namely CEC and SSA [17]. Furthermore, the expression cannot predict the behaviour of expansive soils in the whole of Tanzania.

\begin{tabular}{|c|c|c|}
\hline Equation & Researcher/Author & Parameters employed \\
\hline $\mathrm{S}^{*}=0.00216 \mathrm{PI}^{2.44}$ & $\begin{array}{l}\text { Seed, Woodward and } \\
\text { Lundgren (1962) }\end{array}$ & Plasticity Index \\
\hline $\mathrm{S}=0.00413 \mathrm{SI}^{2.67}$ & $\begin{array}{l}\text { Ranganatham and } \\
\text { Satyanarayana (1965) }\end{array}$ & $\begin{array}{l}\text { Shrinkage Index and Shrinkage } \\
\text { Limit }\end{array}$ \\
\hline $\mathrm{S}=0.0229 \mathrm{PI}^{1.45} \mathrm{c} / \mathrm{w}+6.38$ & $\begin{array}{l}\text { Nayak and } \\
\text { Christensen (1971) }\end{array}$ & $\begin{array}{l}\text { Clay content, Moisture Content } \\
\text { and Plasticity Index }\end{array}$ \\
\hline $\begin{array}{l}\operatorname{LogSP} * *=19.5^{-1}\left[\delta_{d}+\right. \\
0.65 \mathrm{LL}-130.5]\end{array}$ & $\begin{array}{l}\text { Vijayvergiya and } \\
\text { Ghazzaly (1973) }\end{array}$ & $\begin{array}{l}\text { Dry density and Moisture } \\
\text { Content }\end{array}$ \\
\hline $\operatorname{LogSP}=12^{-1}[0.4 \mathrm{LL}-\mathrm{w}+5.5]$ & $\begin{array}{l}\text { Vijayvergiya and } \\
\text { Ghazzaly (1973) }\end{array}$ & Moisture Content \\
\hline $\mathrm{S}=0.66 \times 10^{(0.9 \mathrm{PI} / \mathrm{w}-1.19)}$ & $\begin{array}{l}\text { Schneider and Poor } \\
\text { (1974) }\end{array}$ & $\begin{array}{l}\text { Plasticity Index and Moisture } \\
\text { Content }\end{array}$ \\
\hline $\begin{array}{l}\mathrm{SP}=5.3-147 \mathrm{e} / \mathrm{PI}-\log \mathrm{x} \\
{[0.525 \mathrm{PI}+4.1-0.85 \mathrm{w}]}\end{array}$ & Brackley (1975) & $\begin{array}{l}\text { Void Ratio, Plasticity Index, } \\
\text { and Moisture Content }\end{array}$ \\
\hline $\mathrm{S}=0.000195 \mathrm{LL}^{4.17} \mathrm{~W}^{-2.33}$ & Weston (1980) & Moisture Content \\
\hline $\mathrm{S}=0.2558 \mathrm{e}^{0.08381 \mathrm{PI}}$ & Chen (1975) & Void Ratio, Plasticity Index \\
\hline $\begin{array}{l}\operatorname{LogSP}=-2.132+2.08 \times 10^{-} \\
{ }^{2} \mathrm{LL}+6.65 \times 10^{-4}-2.69 \times 10^{-2} w\end{array}$ & $\begin{array}{l}\text { Komornik and David } \\
\text { (1969) }\end{array}$ & Moisture Content \\
\hline $\begin{array}{l}\mathrm{SP}=3.5817 \times 10^{-2} \mathrm{PI}^{1.12}(\mathrm{C} \\
(w)^{2}+3.7912\end{array}$ & $\begin{array}{l}\text { Nayak and Christen } \\
\text { (1971) }\end{array}$ & $\begin{array}{l}\text { Clay content, Moisture Content } \\
\text { and Plasticity Index }\end{array}$ \\
\hline $\begin{array}{l}\operatorname{LogSP}=1 / 19.5\left[\delta_{\mathrm{d}}+0.6 L L-\right. \\
139.5 w]\end{array}$ & $\begin{array}{l}\text { Vijayvergiya and } \\
\text { Ghazzaly (1973) }\end{array}$ & $\begin{array}{l}\text { Dry Density and Moisture } \\
\text { Content }\end{array}$ \\
\hline $\begin{array}{l}\operatorname{LogSP}=1 / 12[0.44 \mathrm{LL}-w- \\
0.4]\end{array}$ & $\begin{array}{l}\text { Vijayvergiya and } \\
\text { Ghazzaly (1973) }\end{array}$ & Moisture Content \\
\hline $\log S P=5.3-147 \mathrm{e} / \mathrm{PI}$ & Brackely (1973) & Void Ratio and Plasticity Index \\
\hline $\begin{array}{l}\operatorname{LogSP}=2.6386 \delta_{d}+1.3922 \\
+10^{-2} \mathrm{LL}-2.4775\end{array}$ & Elsharief (1987) & $\begin{array}{l}\text { Dry Density and Moisture } \\
\text { Content }\end{array}$ \\
\hline
\end{tabular}

Table 4: Equations to predict swell percent and swell pressure [14].

$*=$ Swell percent and $* *=$ Swell Pressure 
Table 5: Soil classification by their challenging characteristics.

\begin{tabular}{|c|l|}
\hline Soil class & Description of soil characteristics \\
\hline I & $\begin{array}{l}\text { Undisturbed natural soils that typically have few characteristics that would } \\
\text { adversely affect pavement foundation. }\end{array}$ \\
\hline II & $\begin{array}{l}\text { Undisturbed natural soils that typically have high groundwater or restrictive } \\
\text { soil layers. }\end{array}$ \\
\hline III & $\begin{array}{l}\text { Undisturbed natural soils with high shrinkage/swell potential, } \\
\text { compressibility, low bearing strength, and a high-water table that may result } \\
\text { in poor drainage, pavement settlement, and unstable slopes. }\end{array}$ \\
\hline IVa & $\begin{array}{l}\text { Disturbed soils as a result of construction resulting in soils with variable } \\
\text { characteristics. Soils that were originally class III soils. }\end{array}$ \\
\hline IVb & $\begin{array}{l}\text { Disturbed soils as a result of construction resulting in soils with variable } \\
\text { characteristics. Soils that were originally class I or II soils. }\end{array}$ \\
\hline
\end{tabular}

This fact is further expressed by Elarabi [16], who attempted to calibrate 15 such equations with Sudan's local condition of expansive soils, as indicated in Table 4. Elarabi [16] studied 15 expansiveness-predicting equations, and noted that all were based on correlating the effects of one or two variables on the swelling behaviour of the soil. Furthermore, he noted that although each of the equations seemed adequate for the known conditions in the area where developed, several limitations were shown when used at a universal level. He attributed the difference between the results of predicted heave and actual observed heave to the procedure used by researchers in question, the frequency of the test carried out, environmental conditions of the site and the stress history of the soil. He further concluded that to obtain a general equation which is valid for all types of clay soils, local conditions may be very difficult to attain, due to the heterogeneous nature of soil and the conditions surrounding the tests.

\section{ENFORCEMENT REGULATIONS AND DOCUMENTATION}

It is obvious that challenging soils are potentially hazardous to public safety and users of what will be the affected civil or building structures. Apart from said fact, no regulations exist in Tanzania to enforce the engineering fraternity to fully observe the required norms to identify these soils and treat them accordingly during the design period. The Fairfax Country code of ordinance section 107-1(a), for example, has made it clear that construction of any building or structure on land containing challenging (problem) soils is potentially injurious to the health, safety and welfare of the public, and that no such construction shall occur until adequate safeguards are in place. Section 107-1.2 put the challenging soils into four classes, as described in Table 5.

Hitherto there has been no local documentation in each region of Tanzania on the extent of problematic soils and the damage they have caused to road pavements. To address any challenging issue, its presence and negative effect to the welfare of individual persons or to country must be known in advance; hence, there is the utmost need to map locally the extent of these problematic soils' coverage area.

\section{CONCLUSIONS}

Most structural failure of the pavement roadbed or subgrade due to challenging soils arise not because of a lack of adequate engineering solutions, but largely owing to a failure to recognise or understand the following factors: 
- The importance of adequate and timely ground and site investigations;

- The difficulties in specifying, testing and interpreting laboratory and field tests;

- The geological set-up and stratification; and

- Local comparable experience.

These problems do now and then recur, due to the lack of the data base and lack of appreciating the benefit to be accrued through the study of the performance of road pavements that were constructed over challenging soils, and application of gained knowledge to alleviate the problems through back analysis.

\section{RECOMMENDATIONS}

- It should be mandatory for the civil engineers involved with pavement design to understand the type of soil under the road profile, their engineering composition and their characteristics, prior to the use of the same for the optimal performance of the pavement in question.

- Empirical studies have to be conducted now and then with the aim to establish relationships between the performance of existing road pavements which were constructed on challenging soils, with the measure taken to alleviate distress caused by these soils, have to be locally documented.

\section{REFERENCES}

[1] Mgangira, M.B. \& Paige-Green, P., Premature distress of a pavement on expansive black cotton soil in the Horn of Africa, Council for Scientific and Industrial Research (CSIR) Built Environment, 2008.

[2] de Wet, M., Soil behaviour, Stellenbosch University, Department of Civil Engineering Class Notes, 2010.

[3] Burland, B., Broms, B. \& de Mello, F.B., Behaviour of foundations and structures. Proc. of $6^{\text {th }}$ European Conf. On Soil Mechanics and Foundation Engineering, Vienna, 1976.

[4] Fall, M, Azzam, R. \& Sarr, M., Characterization of problematic soils for slope and foundation stability: case study from Dakar, (103), 2006.

[5] The United Republic of Tanzania, Ministry of Works, Pavement and Materials Design Manual, pp. 6.2-6.8, 1999.

[6] O'Flaherty, C.A., Highways, Highway Engineering, 2(3), Edward Arnold London, 1998

[7] Jennings, J.E., Brink, A.B.A. \& Williams, A.A.B., Revised guide to soil profiling for civil engineering purposes in Southern Africa. Transaction of South Africa Institution of Civil Engineers, 15(1) pp. 3-12,1973.

[8] Barden, L., The relation of soil structure to the engineering geology of clay soil. Engineering Geology, (1\&2), pp. 81-102, 1972.

[9] Rogobete, Gh. \& Grozav, A., Soil genesis and problematic soils. Agricultural Science, 45(2), pp. 252-258, 2013.

[10] Saad, S. Problematic Soil, online. www.hti.edu.eg/academic-files/Arabic/1836.pdf.

[11] Fairfax Country, Code of ordinance, Chapter 107, Problem soils, Fairfax, Virginia, 2017.

[12] Briscolland, R. \& Chown, R., Problem Soils: A review from a British perspective. Proc. of Problematic Soils Conf., Nottingham, pp. 53-66, 2001

[13] Mwaipungu, R.R., The influence of problematic soils in design, construction and management of road pavements. Proc. of $10^{\text {th }}$ Int. Conf. On Achievement of UN 
sustainable Development Goals In Innovation, Technology and Engineering, Arusha, Tanzania, pp. 2-10, 2016.

[14] Airey, D., What is the problem with problematic soils? The University of Sydney, 2009.

[15] Bowles, J.E., Foundation Analysis and Design, Fifth Ed. McGraw, Singapore, 1997.

[16] Elarabi, H., Evaluation of predicted equations for swelling potential, Proc. of $16^{\text {th }}$ Int. Conf. On Soil Mechanics and Geotechnical Engineering, Millpress Science, pp. 439-444, 2006.

[17] Cerato, A.B. \& Lutenegger A.J., Activity, relative activity and specific area of fine grained soils. Proc. of $16^{\text {th }}$ Int. Conf. On Soil.

[18] Mechanics and Geotechnical Engineering, Millpress Science, 2006. 